\title{
Human Serum Amyloid A \\ Three Hepatic mRNAs and the Corresponding Proteins in One Person
}

Barbara Kluve-Beckerman, Francis E. Dwulet, and Merrill D. Benson

Departments of Medical Genetics, Medicine, and Biochemistry, Indiana University School of Medicine, Indianapolis, Indiana 46223; Rheumatology Section, Richard L. Roudebush Veterans Administration Medical Center, Indianapolis, Indiana 46202

\begin{abstract}
Serum amyloid A protein (SAA) is a major acute-phase protein in humans and most other mammals. In addition, it is the serum precursor of the major protein constituent of reactive amyloid fibrils. Sequence analyses have identified a number of polymorphic forms of human SAA and amyloid $A$ protein (AA), but the question of the number of genes encoding SAA in the human has not been addressed. In addition, there are insufficient data to predict whether one form of SAA predisposes to amyloid fibril formation. In the present study three separate SAA proteins have been isolated from the plasma of one individual and completely sequenced. While two of the SAA forms (SAA2 $\alpha$ and SAA2 $\beta$ ) differ from each other only at position 71, they differ from the most abundant form (SAA1) at seven and eight other positions, respectively. Nucleotide sequencing of cDNAs from a liver library of this individual identified all three mRNAs coding for these proteins and proved that: $(a)$ the often-reported absence of arginine at the amino terminus of SAA proteins must result from proteolytic processing of the protein; (b) the polymorphism involving histidine and arginine at position 71 is present at the DNA level and therefore is not due to an event at the translational level; (c) there are at least two genes coding for human SAA. Comparison of these data to published sequences of SAA and AA proteins may help in identifying genetically determined forms of SAA which predispose to reactive amyloid fibril formation.
\end{abstract}

\section{Introduction}

Reactive amyloidosis is a fatal condition characterized by extracellular protein deposition in patients with chronic inflammatory diseases. It also develops in a high percentage of individuals with familial Mediterranean fever, an autosomal recessive disease most prevalent in Sephardic Jews, Arabs, and Turks. While a genetic pattern of amyloidosis has not been noted among patients with chronic diseases, its frequent association with familial Mediterranean fever suggests that genetic factors may be involved in its pathogenesis. Such factor(s)

This study was presented in part at the American Rheumatism Association Annual Meeting, Washington, DC (1987. Arthritis Rheum. 30:S15).

Dr. Dwulet is now with Boehringer-Mannhein, Indianapolis, IN. Address reprint requests to Dr. Kluve-Beckerman, Rheumatology Section, Room A772, Richard L. Roudebush VA Medical Center (583/111Rh), 1481 West 10th St., Indianapolis, IN 46202.

Received for publication 25 January 1988 and in revised form 27 June 1988

The Journal of Clinical Investigation, Inc.

Volume 82, November 1988, 1670-1675 could explain the relatively low incidence of amyloidosis seen in American patients with chronic inflammatory diseases.

Amyloid fibrils which form the deposits in reactive amyloidosis are composed primarily of amyloid A protein (AA), ${ }^{1} \mathrm{a}$ degradation product of the acute-phase protein serum amyloid A (SAA). It is commonly hypothesized that increased synthesis of SAA during inflammatory conditions contributes to the development of amyloidosis. High blood concentrations of SAA, however, are seen in most patients with infection and inflammation without resultant amyloid deposition. Thus it appears that additional factors such as metabolic variations, protein processing, and structural gene polymorphisms may influence the likelihood for developing this disease.

An important role for SAA structure in amyloid fibril formation has been suggested by the finding that two major forms of SAA are present in the mouse, but only one form is incorporated into amyloid deposits (1). Because humans represent an exceedingly complex population relative to inbred mouse strains, more human SAA and AA molecules will have to be structurally characterized to evaluate the possibility of selective deposition. To investigate the importance of the primary structure of SAA proteins in amyloidogenesis, we have studied the forms of this protein in one individual at both the DNA and protein levels.

\section{Methods}

Cloning and sequence determination of SAA cDNAs. Liver tissue was obtained at the time of organ donation from patient $\mathrm{COL}$, a man who had suffered accidental traumatic injury. Poly $\mathrm{A}^{+}$RNA isolated from this liver served as the template for the synthesis of cDNA. The cDNA was ligated into the PstI site of pBR322 which, in turn, was used to transform Escherichia coli $\mathrm{HB} 101$ cells. The exact procedures used to construct and the conditions used to screen this library have been described (2). The size of the cDNA inserts was determined and restriction analysis carried out using recombinant plasmid DNA prepared according to the rapid alkaline lysis method (3). For sequence analysis, recombinant plasmid DNA was generated on a larger scale (4) and further purified by ultracentrifugation through ethidium bromide-cesium chloride gradients.

The nucleotide sequences of SAA1 and SAA $2 \alpha$ cDNAs were determined by the chemical degradation procedure (5). The strategy used to sequence SAA2 $\alpha$ cDNA has been described (2). To sequence SAA1 cDNA, pSAA1 was first cleaved within the cDNA by NcoI and the overlapping 5 '-ends radiolabeled using $\left[\gamma-{ }^{32} \mathrm{P}\right] \mathrm{ATP}$ and T4 polynucleotide kinase. Secondary digestions were then performed with PvuI and Hhal which cut the vector at sites relatively close to each end of the cDNA. The resulting two radiolabeled fragments, which together contained all the $\mathrm{CDNA}$ and a small portion of $\mathrm{pBR} 322$, were purified by polyacrylamide gel electrophoresis and sequenced from the NcoI ends.

1. Abbreviations used in this paper: AA, amyloid A protein; SAA, serum amyloid $\mathrm{A}$. 
Sequence determination of SAA $2 \beta$ cDNA was accomplished by the chain termination method (6) using $M 13 \mathrm{mp} 18$ and $M 13 \mathrm{mp} 19$ vectors (7). Initially SAA2 $\beta$ cDNA was excised from $p B R 322$ by digestion with PstI and purified by PAGE. The isolated insert was digested with Sau3A and the resulting fragments ligated to BamHI/PstI- or BamHIdigested replicative form M13. The infection of $E$. coli JM101 cells with recombinant M13 was carried out using competent $E$. coli DH5 cells as a transient host (8).

Southern blot analysis. $18 \mu \mathrm{g}$ of DNA extracted from COL liver tissue (9) was digested with HindIII. The resulting fragments were separated by electrophoresis through a $1 \%$ agarose gel in Tris-borateEDTA buffer and transferred to nitrocellulose. Hybridization was carried out at $65^{\circ} \mathrm{C}$ in $6 \times \mathrm{SSC}(1 \times=0.15 \mathrm{M} \mathrm{NaCl}, 0.015 \mathrm{M}$ sodium citrate, $\mathrm{pH} 7.0$ ), $2 \times$ Denhardt's solution $(50 \times=1 \%$ Ficoll, $1 \%$ polyvinylpyrrolidone, $1 \%$ bovine serum albumin), $100 \mu \mathrm{g}$ of salmon sperm DNA per $\mathrm{ml}, 50 \mathrm{mM}$ sodium phosphate, $\mathrm{pH} 7.0,1 \mathrm{mM}$ EDTA, and $0.2 \%$ sodium dodecyl sulfate as previously described (10). SAA2 $\alpha$ cDNA served as the probe and was radiolabeled with ${ }^{32} \mathrm{P}$ by nick translation. Final washing was at $65^{\circ} \mathrm{C}$ in $0.2 \times \mathrm{SSC}, 0.2 \%$ sodium dodecyl sulfate.

$S A A$ protein purification and sequence determination. Blood was obtained from patient $\mathrm{COL}$ at the time of organ donation. Radioimmunodiffusion assays indicated that the level of SAA in the plasma was significantly elevated. Purification of SAA from plasma was accomplished using the protocol developed by Dwulet et al. (11), which consisted of ultracentrifugation through potassium bromide density gradients, Sepharose CL6B chromatography, and reverse-phase high performance liquid chromatography (HPLC) using a Synchropak RP-P, C-18, column. SAA-containing fractions were identified by immunoreactivity with anti-AA protein antiserum. Digestion of purified SAA with trypsin, purification of tryptic peptides, and determination of peptide sequences and amino acid compositions were performed as previously described (11).

\section{Results}

Selection and sequence determination of three distinct $S A A$ cDNA clones. Three distinct SAA cDNA clones, designated pSAA1, pSAA $2 \alpha$, and pSAA2 $\beta$, were isolated from the cDNA library constructed using poly $\mathrm{A}^{+}$RNA extracted from a single liver. The cloning and sequence determination of pSAA2 $\alpha$ (previously referred to as pSAA82) has been described (2). The cDNA inserts of the three clones were readily distinguished from each other by the particular cleavage pattern which resulted from digestion with PstI and NcoI (Fig. 1). SAA1 cDNA was cleaved internally by PstI as evidenced by its excision from pBR322 as two fragments; the larger of the two fragments was in turn cut by NcoI. SAA $2 \alpha$ cDNA, excised as an intact fragment of $\sim 575$ base pairs, was not cut internally by PstI; however, it was cleaved by NcoI. SAA2 $\beta$ cDNA was not cut by either enzyme.

The nucleotide sequences determined for SAA1, SAA2 $\alpha$, and SAA2 $\beta$ cDNAs confirm that they encode SAA and show that all three extend from a 5 '-untranslated region through a poly A tail. SAA2 $\alpha$ and SAA2 $\beta$ cDNAs have identical nucleotide sequences within their coding regions except for the second position of codon 71 , at which SAA $2 \alpha$ cDNA has adenine and SAA2 $\beta$ cDNA guanine (Fig. 2). The underlined sequence CCATGG in SAA1 and SAA $2 \alpha$ cDNAs encompasses codon 71 and is the recognition sequence for NcoI.

While the nucleotide sequence of SAA1 cDNA differs from the sequences of SAA2 $\alpha$ and SAA2 $\beta$ cDNAs at a number of positions, all but one of the polymorphic sites are in the $3^{\prime}$-half of the sequence (Fig. 2). Single-base differences between SAA1 cDNA and SAA $2 \alpha$ and SAA $2 \beta$ cDNAs that give rise to amino

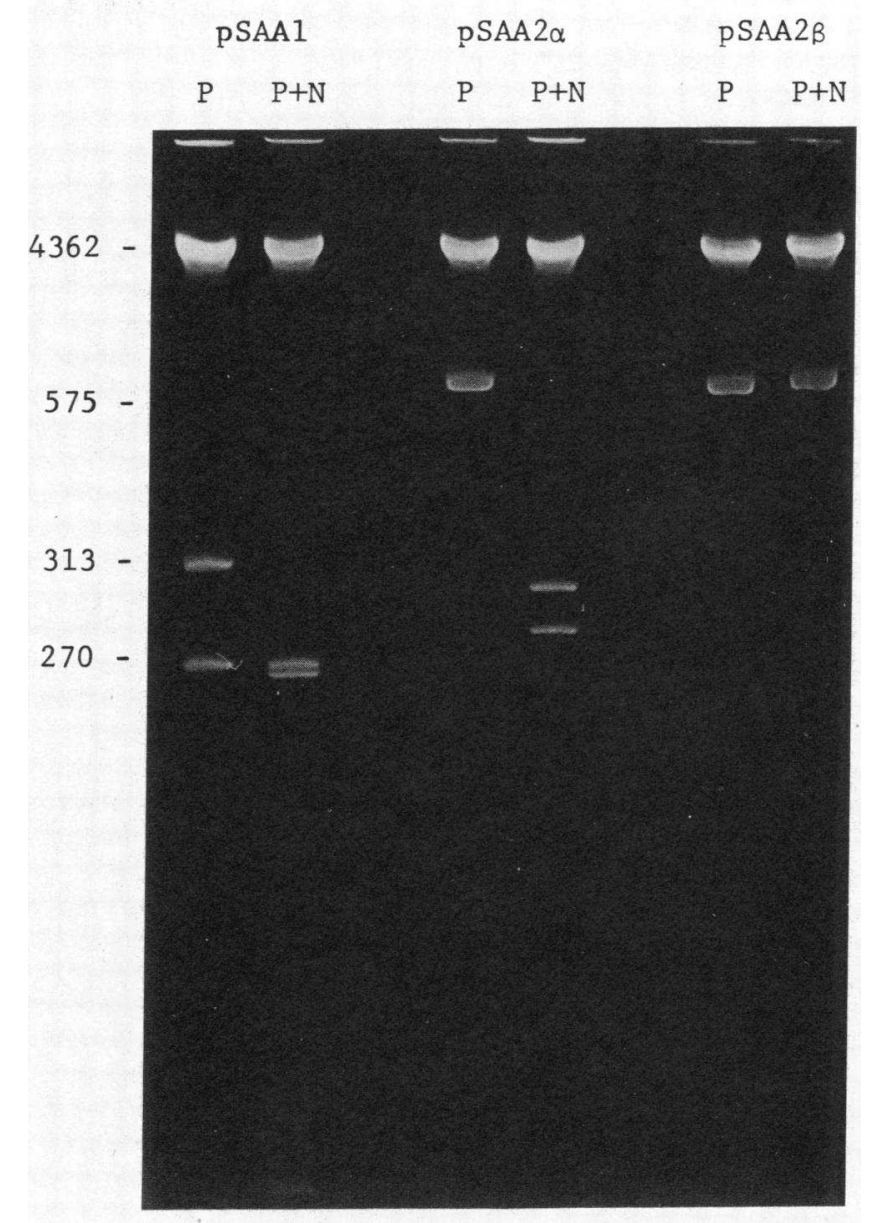

Figure 1. Digestion of pSAA1, pSAA2 $\alpha$, and pSAA2 $\beta$ with PstI and PstI plus NcoI. Recombinant plasmid DNA $(1 \mu \mathrm{g})$ was digested either with PstI $(P)$ or with PstI, followed by NcoI $(P+N)$. After digestion, the DNA was subjected to electrophoresis through a $5 \%$ polyacrylamide gel in Tris-borate-EDTA buffer at $200 \mathrm{~V}$. DNA was stained with ethidium bromide and visualized under ultraviolet light. Numbers at the left are fragment sizes in base pairs. The band at 4362 base pairs represents pBR322.

acid differences occur in the first or second positions of codons $52,57,60,68,84$, and 90 . Single-base substitutions also are present in codons 54 and 78 , but because the heterogeneity is in the third position, both codons specify the same amino acid. The third position cytosine of codon 54 in SAAl cDNA is noteworthy, however, since it is within the recognition sequence of PstI. Additional heterogeneity is seen in codon 69, where all three bases of SAA1 cDNA differ from those of SAA $2 \alpha$ and SAA2 $\beta$ cDNAs. Table I presents a list of the codons and deduced amino acids which are polymorphic among the cDNAs.

Determination of three different SAA plasma protein sequences. SAA-containing material, purified from plasma by ultracentrifugation through potassium bromide gradients and chromatography over sepharose CL6B, was fractionated into four forms by reverse phase HPLC (Fig. 3). Sequence analysis showed that two of the four forms, those present in peaks III and IV, were identical to each other, except for the presence of arginine at the amino terminus of one (peak III) and not the other (peak IV). The amino acid sequence of these forms was 


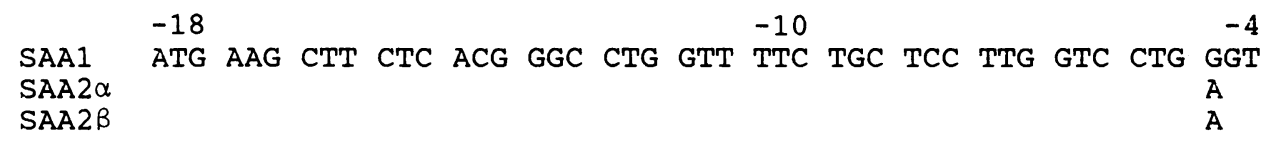

SAA1 GTC AGC AGC CGA AGC TTC TTT TCG TTC CTT GGC GAG GCT TTT GAT $\operatorname{SAA} 2 \alpha$

SAA2 $\beta$

SAA1 GGG GCT CGg GAC ATG TGG AGA GCC TAC TCT GAC ATG AGA GAA GCC

SAA2 $\alpha$

SAA2B

SAA1

$\operatorname{SAA} 2 \alpha$

SAA2 $\beta$

AAT TAC ATC GGC TCA GAC AAA TAC TTC CAT GCT CGG GGG AAC TAT

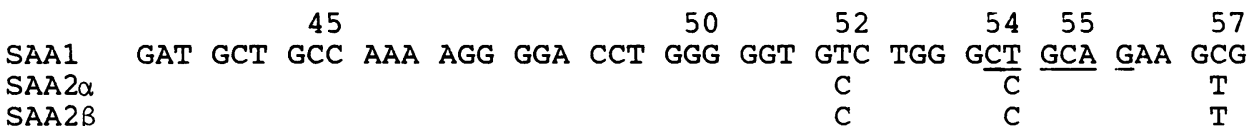

$\begin{array}{llllll}60 & 65 & 68 & 69 & 70 & 71\end{array}$

SAA1

SAA2 $\alpha$

SAA2 $\beta$

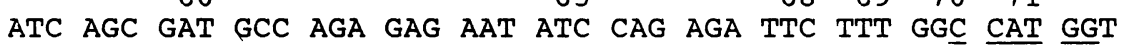 A $C$ C ACA
A $\quad$ C ACA $\quad$ G

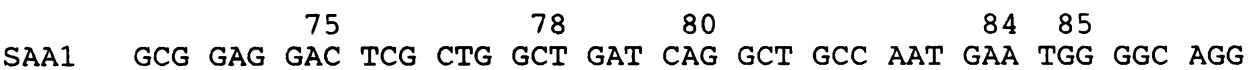

SAA2 $\alpha$

SAA2 $\beta$

GCG GAG GAC TCG CTG GCT GAT CAG GCT GCC AAT GAA
C
C

SAA1 AGT GGC AAA GAC CCC AAT CAC TTC CGA CCT GCT GGC CTG CCT GAG

$\operatorname{SAA} 2 \alpha$

SAA2 $\beta$

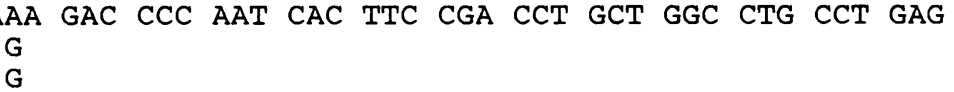

Figure 2. Nucleotide sequences of the coding regions of the three cloned COL SAA cDNAs. Blank spaces in the sequences of SAA $2 \alpha$ and SAA $2 \beta$ cDNAs indicate identity with SAA1 cDNA. The underlined nucleotides spanning codons 54-56 and 70-72 are the recognition sequences for PstI and NcoI, respectively.

SAA $2 \alpha$

104

AAA TAC TGA

SAA $2 \beta$

the same as that encoded by SAA1 cDNA (Fig. 4); hence, peak III material has been designated SAA1 and peak IV material SAA1 des Arg. These two forms constituted the majority of SAA isolated from the donor's plasma.
The sequences of the other two forms, isolated as peaks I and II (Fig. 3), were also identical to each other, except that peak II material lacked arginine at the amino terminus. Both of these forms were composed of two SAA molecules differing

Table I. Nucleotide and Amino Acid Differences among SAA cDNAs and Proteins

\begin{tabular}{|c|c|c|c|c|c|c|}
\hline & \multicolumn{6}{|c|}{ Codon and amino acid } \\
\hline & -4 & 52 & 54 & 57 & 60 & \\
\hline SAA 1 & GGT-Gly & GIC-Val & GCI-Ala & GCGG-Ala & GAT-Asp & \\
\hline $\operatorname{SAA} 2 \alpha$ & $\underline{\text { AGT-Ser }}$ & GCCC-Ala & GCEC-Ala & GTG-Val & $\underline{\mathrm{A} A T-\mathrm{Asn}}$ & \\
\hline \multirow[t]{2}{*}{$\mathrm{SAA} 2 \beta$} & $\underline{\text { AGT-Ser }}$ & GCCC-Ala & GCE-Ala & GIG-Val & $\underline{\text { AAT-Asn }}$ & \\
\hline & 68 & 69 & 71 & 78 & 84 & 90 \\
\hline SAA1 & TTC-Phe & TTT-Phe & CA-T-His & GCI-Ala & GAA-Glu & AAA-Lys \\
\hline SAA $2 \alpha$ & CTC-Leu & ACA-Thr & CA-T-His & GCㄷ-Ala & AAA-Lys & A $\underline{\text { AA-Arg }}$ \\
\hline $\mathrm{SAA} 2 \beta$ & CTC-Leu & ACA-Thr & CㅁT-Arg & GCE-Ala & AAA-Lys & A $\underline{\text { AA-Arg }}$ \\
\hline
\end{tabular}




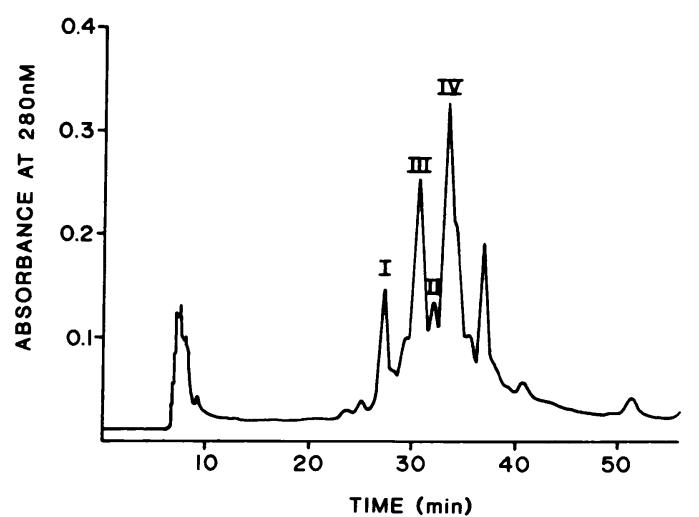

Figure 3. Reverse phase HPLC separation of $9.3 \mathrm{mg}$ of the SAA fraction isolated from a Sepharose CL6B column on a Synchropak RPP, $\mathrm{C}-18$, column $(1 \times 25 \mathrm{~cm})$. Initial buffer $(A)$ was $0.1 \%$ trifluoroacetic acid, water and the final buffer $(B)$ was $0.1 \%$ trifluoroacetic acid, $90 \%$ 2-propanol. The sample was applied in $5 \%$ glacial acetic acid and the proteins eluted using a 30-50\% buffer B gradient in $60 \mathrm{~min}$ at a flow rate of $2 \mathrm{ml} / \mathrm{min}$.

by having either a histidine or an arginine residue at position 71. The histidine-containing sequence (SAA2 $\alpha$, Fig. 4) matched the amino acid sequence derived from SAA $2 \alpha$ cDNA, while the arginine-containing sequence (SAA2 $\beta$, Fig. 4) was identical to the sequence specified by SAA2 $\beta$ cDNA. The protein sequence data show that all three SAA DNA sequences had been expressed in the donor individual. Thorough analysis of chromatographic profiles, along with amino acid compositions and sequence determinations, did not indicate the presence of any other SAA species.

Southern analysis of genomic DNA from patient COL. In addition to RNA, total genomic DNA was isolated from a portion of the same liver. Aliquots of the DNA were digested individually with HindIII, PstI, and PvuII and then subjected to Southern analysis using SAA2 $\alpha$ cDNA as probe (Fig. 5). The probe detected SAA gene sequences in two HindIII fragments (4.6 and $1.1 \mathrm{~kb})$. It also hybridized to a 3.6-kb HindIII fragment, although hybridization to this fragment was weak in comparison. Four PstI fragments $(2.8,1.9,1.7$, and $1.2 \mathrm{~kb})$ and four PvuII fragments $(4.1,2.8,2.2$, and $1.7 \mathrm{~kb})$ were detected by the probe.

\section{Discussion}

Three different forms of SAA were expressed in one individual as shown by the isolation of three SAA plasma proteins. Multiple forms were first indicated when SAA was fractionated by reverse-phase HPLC into four peaks of protein AA-immunoreactive material. Complete amino acid sequence determination of each of the forms corresponding to the four peaks revealed three different SAA structures. Concurrently, three full-length SAA cDNAs were cloned from a cDNA library constructed using mRNA extracted from the liver of the same individual. Double digestion of the clones with PstI and NcoI generated three different cleavage patterns. The nucleotide sequences determined for the cDNAs showed that each of them encoded an SAA protein and, in addition, confirmed the presence or absence of recognition sequences for PstI and NcoI. The amino acid sequences specified by the three cDNAs were identical to the sequences of the three isolated proteins.
Interestingly, the three SAA protein sequences described in this report are the same as those isolated from another unrelated individual (11). In both studies, all three forms were found with and without an amino-terminal arginine. The three cDNAs reported here and the SAA cDNA cloned by Sipe et al. (12) have a codon specifying arginine at the amino terminus. Therefore, the amino-terminal heterogeneity observed by us and reported by a number of investigators (13-15) most likely represents proteolytic processing rather than a genetically determined polymorphism.

A comparison of the three SAA structures in this individual shows that SAA $2 \alpha$ and SAA $2 \beta$ have a single amino acid difference specified by a single nucleotide change. They differ, however, from SAA1 at a number of sites. Between the coding regions of SAA 1 and SAA $2 \alpha$ cDNAs there are 12 nucleotide differences of which 8 are replacement changes, that is, they result in amino acid differences. Between SAA1 and SAA2 $\beta$ cDNAs there are 13 nucleotide differences resulting in nine amino acid changes. This high rate of replacement changes compared to silent site changes also has been noted as an unusual feature of mouse SAA1 and SAA2 gene evolution. Lowell et al. (16) have proposed that the heterogeneous proteins resulting from replacement substitutions in the mouse SAA genes provide a selective advantage and thus have helped fix the genes in the population.

Of the three protein forms described here, SAA1 appears to be the most common. This polymorph was the predominant form in our donor and also in another individual (11). Furthermore, its sequence matches the amino acid sequence derived from the cDNA characterized by Sipe et al. (12) and except for the lack of valine/alanine polymorphisms at positions 52 and 57 , is identical to the amino acid sequence determined by Parmelee et al. (17) for SAA isolated from pooled human serum. The presence of phenylalanine at positions 68 and 69, glutamic acid at 84 , and lysine at 90 in SAA1 also makes it similar to an SAA purified by Sletten et al. (18) from the plasma of a single individual, which unlike SAA1, has asparagine rather than aspartic acid at positions 23,60 , and 75 . The combination of leucine at position 68 and threonine at 69 , as occurs in SAA2 $\alpha$ and SAA2 $\beta$, has been reported less frequently than phenylalanine at the same positions. Leucine and threonine at positions 68 and 69 , as well as arginine at 71 , were seen in the first completely sequenced AA protein which was isolated from a person with familial Mediterranean fever (19). Residues 1 through 76 of SAA2 $\beta$ described here and by Dwulet et al. (11) perfectly match the sequence of this AA protein. It should be noted that the sequence of SAA $2 \beta$ cDNA, except for the substitution of cytosine for thymine in the third position of codon 54 (and the consequential loss of a PstI site), is identical to the coding region sequence of an SAA gene characterized by Woo et al. (20).

The presence of three DNA sequences in one individual is proof that humans have a minimum of two genes for SAA. Each of the three sequences could have a separate genetic locus. Alternatively, two of the sequences could be alleles at one locus, in which case the three sequences would represent two genes. Current evidence favors the latter possibility. First, the concentration of SAAl in the plasma was significantly higher than the concentration of either SAA $2 \alpha$ or SAA2 $\beta$. If all forms were equally expressed, the level of SAA1 would predominate over that of SAA $2 \alpha$ or SAA $2 \beta$ in an individual who is homozygous at one genetic locus (SAA1) and heterozygous 


\begin{tabular}{|c|c|}
\hline $\begin{array}{l}\text { SAA1 } \\
\text { SAA2 } \alpha \\
\text { SAA2 }\end{array}$ & $\begin{array}{cc}20 & 25 \\
\text { Asp-Met-Trp-Arg-Ala-Tyr-Ser-Asp-Met-Arg-Glu-Ala-Asn-Tyr-Ile- } & 30\end{array}$ \\
\hline $\begin{array}{l}\text { SAA1 } \\
\text { SAA2 } \alpha \\
\text { SAA2B }\end{array}$ & $\begin{array}{cc}35 & 40 \\
\text { Gly-Ser-Asp-Lys-Tyr-Phe-His-Ala-Arg-Gly-Asn-Tyr-Asp-Ala-Ala- }\end{array}$ \\
\hline $\begin{array}{l}\text { SAA1 } \\
\text { SAA2 } \alpha \\
\text { SAA2 } \beta\end{array}$ & 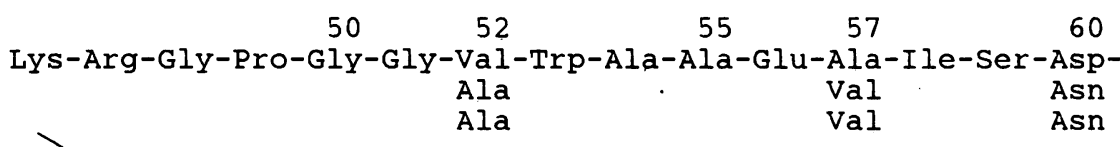 \\
\hline $\begin{array}{l}\text { SAA1 } \\
\text { SAA2 } \alpha \\
\text { SAA2 }\end{array}$ & 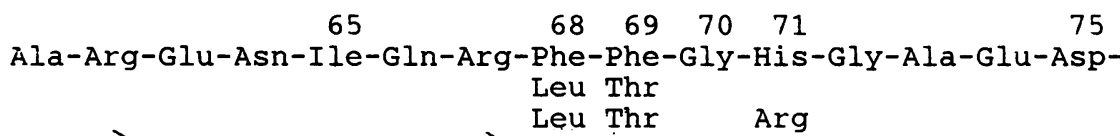 \\
\hline
\end{tabular}

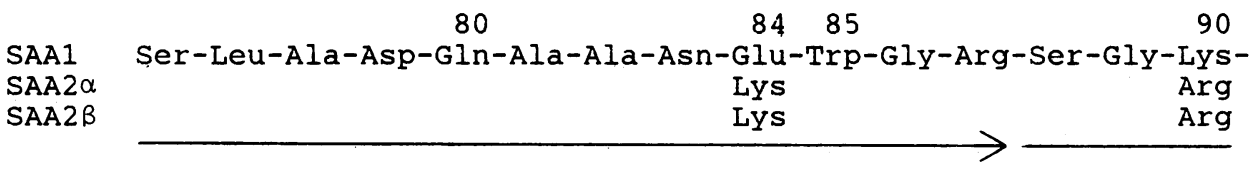

$\begin{array}{lccr}\text { SAA1 } & 95 & 100 & 104 \\ \text { SAA2 } \alpha & \text { Asp-Pro-Asn-His-Phe-Arg-Pro-Ala-Gly-Leu-Pro-Glu-Lys-Tyr } \\ \text { SAA2 } 3 & & \end{array}$

Figure 4. Complete amino acid sequences of COL SAA1, SAA $2 \alpha$, and SAA2 $\beta$ plasma proteins. Blank spaces in the sequences of SAA $2 \alpha$ and SAA $2 \beta$ indicate identity with SAA1. Tryptic peptides used to determine the structure of SAA1 are shown by the arrows. One additional peptide was seen for SAA2 $\alpha$ because of lysine at position 84 and two additional peptides for SAA2 $\beta$ due to arginine at 71 and lysine at 84 . at another locus (SAA2 $\alpha$ and SAA2 $\beta$ ). Secondly, Southern analysis of HindIII-digested total DNA isolated from the donor's liver showed that SAA gene sequences were contained in two strongly hybridizing fragments, 4.6 and $1.1 \mathrm{~kb}$ in length (Fig. 5).

Data not shown indicate that the 4.6-kb HindIII fragment (Fig. 5) contains a portion of one SAA gene. The 5'-end of this fragment is defined by a HindIII site present in an intron situated between the sequences encoding amino acids 12 and 13 , and its $3^{\prime}$-end by a HindIII site located at least $2.8 \mathrm{~kb}$ beyond the $3^{\prime}$-end of the gene. The $1.1 \mathrm{~kb}$ HindIII fragment (Fig. 5) presumably contains sequences of another SAA gene. The $3.6 \mathrm{~kb}$ HindIII fragment (Fig. 5) must also have some degree of sequence identity with SAA $2 \alpha$ cDNA. However, we feel that the percent homology among the SAA cDNAs, over $92 \%$, is too high and the relative hybridization strength of the $3.6 \mathrm{~kb}$ fragment too weak for this fragment to correspond to the SAA1, SAA $2 \alpha$, or SAA $2 \beta$ gene. It may contain sequences of a more divergent SAA gene or, less likely, sequences at the end of one of the genes which are still within the region recognized by the cDNA probe.

The restriction fragment patterns generated by enzymes other than HindIII are more complex and show that SAA gene sequences are contained in a least four PstI and four PvulI fragments (Fig. 5). To use these patterns to estimate gene number one must take into account the known restriction site for PstI in SAA1 cDNA, the possibility of additional PstI or PvuII sites within the introns of SAA genes, and the fact that the cDNA probe may not hybridize to fragments which either lack or contain only short regions of coding sequence. Even so, the number of PstI and Pvull fragments seen in Fig. 5 suggests the presence of at least two SAA genes.

A human SAA gene family consisting of two nearly identical genes and a third somewhat divergent gene would be analo- 


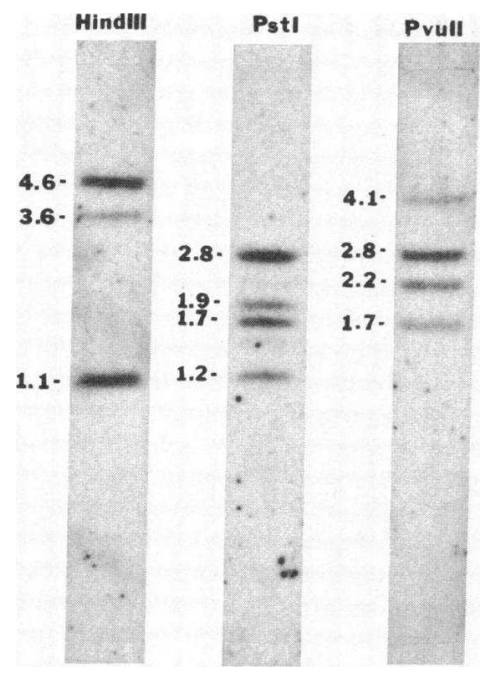

Figure 5. Autoradiograph of Southern analysis of HindIII, PstI, and PvuII-digested COL genomic DNA. The probe was ${ }^{32} \mathrm{P}$-labeled SAA $2 \alpha$ cDNA. The most stringent washing was performed at $65^{\circ} \mathrm{C}$ in $0.2 \times$ SSC ( $30 \mathrm{mM} \mathrm{NaCl}, 3 \mathrm{mM}$ sodium citrate, $\mathrm{pH} 7.0$ ), $0.2 \%$ SDS. Numbers at the left are fragment sizes in kilobases.

gous to the mouse SAA gene family, although a pseudogene related to the murine SAA1 and SAA2 genes also has been identified $(16,21)$. Mouse SAA genes $(16,21)$ and cDNAs $(22$, 23 ) and mouse AA protein (24) have been characterized exclusively from inbred strains. Consequently, there are only two known sequences rather than the multiple number of sequences seen in the human population, which presumably represent allelic gene products. Since only one of the mouse genes appears to encode SAA involved in amyloid formation (1), it will be interesting to determine if all human amyloid fibril sequences are products of the same gene. Toward elucidating the genetic heterogeneity of human SAA we have completely characterized the three forms of SAA expressed in one person. A better understanding of the nature and number of SAA structural variants will allow us to ask if a particular form(s) is common to all reactive amyloid patients, and thus test the hypothesis that the primary structure of SAA helps determine its amyloid-forming potential.

\section{Acknowledgments}

This work was supported by Veterans Administration Medical Research (MRIS 583-0888) and grants from the U. S. Public Health Service (RR-00750 (GCRC)), National Institute of Arthritis, Diabetes and Digestive and Kidney Diseases (AM-20582, DK-34881, AM-7448, and AM-35482), the Arthritis Foundation, the Grace M. Showalter Trust, the Marion E. Jacobson Fund, and the National Science Foundation.

\section{References}

1. Hoffman, J. S., L. H. Ericsson, N. Eriksen, K. A. Walsh, and E. P. Benditt. 1984. Murine tissue amyloid protein AA: $\mathrm{NH}_{2}$-terminal sequence identity with only one of two serum amyloid protein (apoSAA) gene products. J. Exp. Med. 159:641-646.

2. Kluve-Beckerman, B., G. L. Long, and M. D. Benson. 1986. DNA sequence evidence for polymorphic forms of human serum amyloid A (SAA). Biochem. Genet. 24:795-803.

3. Ish-Horowicz, D., and J. F. Burke. 1981. Rapid and efficient cosmid cloning. Nucleic Acids Res. 9:2989-2998.

4. Clewell, D. B., and D. R. Helinski. 1972. Effect of growth conditions on the formation of the relaxation complex of supercoiled ColE 1 deoxyribonucleic acid and protein in Escherichia coli. J. Bacteriol. 110:1135-1146.

5. Maxam, A. M., and W. Gilbert. 1980. Sequencing end-labeled DNA with base-specific chemical cleavages. Methods Enzymol. 65:499-560.

6. Sanger, F., S. Nicklen, and A. R. Coulson. 1977. DNA sequencing with chain terminating inhibitors. Proc. Natl. Acad. Sci. USA. 74:5463-5467.

7. Messing, J., R. Crea, and P. H. Seeburg. 1981. A system for shotgun DNA sequencing. Nucleic Acids Res. 9:309-321.

8. Bethesda Research Laboratories Technical Services. M13 cloning/dideoxy sequencing instruction manual. Bethesda Research Laboratories, Gaithersburg, MD.

9. Madisen, L., D. I. Hoar, C. Holroyd, M. Crisp, and M. E. Hodes. 1987. DNA banking: The effects of storage of blood and isolated DNA on the integrity of DNA. Am. J. Med. Genet. 27:379-390.

10. Kluve-Beckerman, B., S. L. Naylor, A. Marshall, J. C. Gardner, T. B. Shows, and M. D. Benson. 1986. Localization of human SAA gene(s) to chromosome 11 and detection of DNA polymorphisms. Biochem. Biophys. Res. Commun. 137:1 196-1204.

11. Dwulet, F. E., D. K. Wallace, and M. D. Benson. 1988. Amino acid structures of multiple forms of amyloid related serum protein SAA from a single individual. Biochemistry. 27:1677-1682.

12. Sipe, J. D., H. R. Colten, G. Goldberger, M. D. Edge, B. F. Tack, A. S. Cohen, and A. S. Whitehead. 1985. Human serum amyloid A (SAA): Biosynthesis and postsynthetic processing of preSAA and structural varients defined by complementary DNA. Biochemistry. 24:2931-2936.

13. Benditt, E. P., N. Eriksen, M. A. Hermodson, and L. H. Ericsson. 1971. The major proteins of human and monkey amyloid substance: Common properties including unusual $\mathrm{N}$-terminal amino acid sequences. FEBS (Fed. Eur. Biochem. Soc.) Lett. 19:169-173.

14. Franklin, E. C., M. Pras, M. Levin, and B. Frangione. 1971. The partial amino acid sequence of the major low molecular weight component of two human amyloid fibrils. FEBS (Fed. Eur. Biochem. Soc.) Lett. 22:121-123.

15. Sletten, K., G. Husby, and J. B. Natvig. 1976. The complete amino acid sequence of an amyloid fibril protein AA of unusual size (64 residues). Biochem. Biophys. Res. Commun. 69:19-25.

16. Lowell, C. A., D. A. Potter, R. S. Stearman, and J. F. Morrow. 1986. Structure of the murine serum amyloid A gene family. J. Biol. Chem. 261:8442-8452.

17. Parmelee, D. C., K. Titani, L. H. Ericsson, N. Eriksen, E. P. Benditt, and K. A. Walsh. 1982. Amino acid sequence of amyloid-related apoprotein (apoSAA $A_{1}$ ) from human high-density lipoprotein. Biochemistry. 21:3298-3303.

18. Sletten, K., G. Marhaug, and G. Husby. 1983. The covalent structure of amyloid-related serum protein SAA from two patients with inflammatory disease. Hoppe-Seyler's Z. Physiol. Chem. 364:1039-1046.

19. Levin, M., E. C. Franklin, B. Frangione, and M. Pras. 1972. The amino acid sequence of a major nonimmunoglobulin component of some amyloid fibrils. J. Clin. Invest. 51:2773-2776.

20. Woo, P., J. Sipe, C. A. Dinarello, and H. R. Colten. 1987. Structure of a human serum amyloid $A$ gene and modulation of its expression in transfected L cells. J. Biol. Chem. 262:15790-15795.

21. Yamamoto, K. I., N. Goto, J. Kosaka, M. Shiroo, Y. D. Yeul, and S. Migita. 1987. Structural diversity of murine serum amyloid A genes. Evolutionary implications. J. Immunol. 139:1683-1688.

22. Yamamoto, K. I., and S. Migita. 1985. Complete primary structures of two major murine serum amyloid A proteins deduced from cDNA sequences. Proc. Natl. Acad. Sci. USA. 82:2915-2919.

23. Stearman, R. S., C. A. Lowell, C. G. Peltzman, and J. F. Morrow. 1986. The sequence and structure of a new serum amyloid $A$ gene. Nucleic Acids. Res. 14:797-809.

24. Dwulet, F. E., and M. Benson. 1987. Primary structure of amyloid fibril protein AA in azocasein-induced amyloidosis of CBA/J mice. J. Lab. Clin. Med. 110:322-329. 